\title{
Kinetic Parameters for the Thermal Decomposition of Forest Waste Using Distributed Activation Energy Model (DAEM)
}

\author{
Alok DHAUNDIYAL ${ }^{1 *}$, Pramod TEWARI ${ }^{2}$ \\ ${ }^{1}$ Department of Mechanical Engineering, Himgiri Zee University, Dehradun, U.K, India \\ ${ }^{2}$ Department of Mechanical Engineering, College of Technology, Govind Ballabh Pant University of \\ Agriculture and Technology, Pantnagar, U.K, India
}

\begin{abstract}
The purview of paper pivoted around the pyrolysis decomposition of forest waste (pine needle litter) by thermogravimetric analysis (TGA). Experiments were carried out in the presence of Nitrogen atmosphere. The experimental data was compared with those obtained by numerical solution of distributed activation energy model (DAEM). Asymptotic expansion is adopted to evaluate the pre-exponential factor, mean activation energy and variance. The correction factor $B_{i}$ has been invoked to describe accurately the differential thermogravitmeric curves of thermal decomposition of pine needles.
\end{abstract}

Keywords - Forest waste; pyrolysis; thermogravimetric analysis (TGA); kinetic parameters; distributed activation energy model (DAEM)

\begin{tabular}{|lll}
\hline Nomenclature & & \\
$f(E)$ & Distribution function & $\mathrm{kJ} / \mathrm{mol}$ \\
$M_{i}$ & Total mass of volatile component released due to $i$ reaction & - \\
$A$ & Frequency factor & $\mathrm{min}^{-1}$ \\
$E_{i}$ & Activation energy for $i$ th reaction & $\mathrm{kJ} \mathrm{mol}^{-1}$ \\
$\mathrm{FC}$ & Fixed carbon content & $\mathrm{wt} \%$ \\
$\mathrm{VC}$ & Volatile content & $\mathrm{wt} \%$ \\
$\mathrm{HHV}$ & Higher heating value & $\mathrm{MJ} \mathrm{kg}^{-1}$ \\
$R$ & Universal gas constant & $\mathrm{kJ} \mathrm{mol}^{-1} \mathrm{~K}^{-1}$ \\
$T$ & Temperature & $\mathrm{K}$ \\
$k_{i}$ & Rate constant & $\mathrm{min}^{-1}$ \\
$\theta$ & Heating rate & $\mathrm{K} \mathrm{min}$ \\
$T_{0}$ & Initial temperature & $\mathrm{K}$ \\
$t$ & Time & $\mathrm{min}^{-1}$ \\
$M_{t}$ & Mass of sample at given time $(t)$ & $\mathrm{mg}$ \\
$M_{0}$ & Initial mass of the sample & $\mathrm{mg}$ \\
$M_{\mathrm{f}}$ & Residual mass at the end of process & $\mathrm{mg}$ \\
$L . H . S$. & Left Hand Side & \\
$Y$ & Lambert $W$ function & \\
$\tau$ & Time scale & \\
$U$ & Heaviside step function &
\end{tabular}

\footnotetext{
* Corresponding author.
}

E-mail address: alok.dhaundiyal@hzu.edu.in 


\section{INTRODUCTION}

The chir pine (Pinus roxburghii) forests encompass 97.4 thousand acres or $16.15 \%$ of the total forest land of Uttarakhand state. According to Forest Department of India, Dehradun, a massive forest fire in 1995 engulfed 14.7 thousand acres of valuable forest area through 2,272 forest fire incidents took place in Uttarakhand state [1]. In addition to the forest inferno, there are numerous collateral damage occurs to the ecological system, such as damage the top fertile layer of soil, depletion of the ground water and hinder the growth of grass, which results in scarcity of fodder for livestock. Therefore, an attempt has been made to overcome the demerits of pine needles by using them for synthesis of bio-fuel as a by-product. Before undergoing any thermos-chemical process, it is very important to evaluate the kinetic parameters of its constitutes which in turn decompose into tar and volatile gases. There are various models have been proposed to exhibit pyrolysis of biomass. But the most accurate and well defined approach for modeling the biomass pyrolysis is distributed activation energy model (DAEM) [2]-[5].

Mathematically, decomposition of biomass and knowing it kinetics is very complex as several parallel decomposition reactions occur and their mechanisms are unknown. Though, various mathematical modeling have been adopted to describe the process of degradation of biomass [6], [7]. There is also a model that is usually implemented in case of ultimate number parallel decomposition reaction, is also known as lumped kinetic model [8], [9]. DAEM has been recently used in the mathematical study of pyrolysis process. This model is based on the multi reaction models as it presumes that many decomposition reactions of $n$ th-order with distributed activation energies happen simultaneously [10], [11]. The principle of the lumped kinetic model and DAEM are very similar, yet dichotomy between lumped kinetic model and distributed activation energy mode is the number of expected decomposition reactions. Around100 decomposition reactions take place in lumped kinetic model, which would be approaching the distributed activation kinetic model. DAEM is also used for the description of thermal decomposition of fossil fuels and other thermally degradable substances [12], [13].

The main focus of this work is to know suitability of DAEM for predicting the thermal decomposition of pine needles that comprises several other compounds process in more steps and to evaluate the kinetic parameters for the constitutes components of pyrolysis of pine needles.

\section{Material AND MethodS}

\subsection{Experimental Details}

The chemical characteristic of pine needle samples is measured with the help of elemental analyser (Perkin Elmer 2400 series) and the calorific value is evaluated by using the constant volume bomb calorimeter. Pyrolysis of pine needles was performed by using the thermo gravimetric equipment, SDT Q600 (TA, Perkin Elmer etc.). A horizontal TG/DSC holder was used to nullify the Archimedes effect. In order to measure the actual sample and furnace temperature, thermocouple types R (Platinum-Rhodium-13\%/Platinum) were used. Table 1 shows chemical composition of pine needles. 
TABle 1. Characterization of Pine NeEdles SAMPle Composition

\begin{tabular}{llllllll}
\hline Component & Ash, \% & C, \% & H, \% & O, \% & FC, \% & VC, \% & $\begin{array}{l}\text { HHV, } \\
\mathbf{M J} / \mathbf{k g}\end{array}$ \\
\hline Content, mass\% & 2.1 & 54.05 & 5.34 & 32.58 & 14.6 & 73.1 & 20.7 \\
\hline
\end{tabular}

\subsection{Distributed Activation Energy Model (DAEM)}

The concept of DAEM was given by Vand [14]. Pitt [15] used it for coal devolatilisation problems. Later on adopted by Hanbaba and his co-workers [16] and Anthony [17], [18]. The model assumes that the decomposition mechanism requires a multi-step, independent, parallel and the first order chemical reactions which has different activation energies and reflects variations in the strengths of components of biomass.

Mathematical solution of this model may require calculation of double integral, involving rapidly varying functions and therefore creates significant numerical complication. So, in this regard the asymptotic method was used to solve integrals and thereby allow robust calculation of DAEM solution, which also includes "Double exponential" term. Previously, the approximations to the DAEM solution, mainly those seeking to convert the DAEM to SFOR (simple first order reaction) model, are facing the extrapolating difficulties to the different heating regimes. Therefore, it is very difficult to find the distribution function $f(E)$ from experimental measurements. In 1993, Niksa and Lau [19] derived the relationship between the DAEM and the SFOR with an assumption of keeping activation energy fixed, and estimating nominal rate constant, $k$, which varies with time. Later on, their work was revamped by Suuberg [20] who uses a Heaviside step function approximation to double exponential which increases from zero to one at an energy that varies with time.

The frequency factor can be related to activation energy or temperature [21] as:

$$
\begin{gathered}
\frac{\mathrm{d} m_{i}}{\mathrm{~d} t}=-k_{i}\left(M_{i}-m_{i}\right), \\
k_{i}=A_{0 t} e^{\frac{-E_{i}}{R T}}
\end{gathered}
$$

where $M_{i}$ represents the total released mass of the pine needles due to reaction $i$ and $A_{0}$ is a frequency or pre-exponential factor and $E_{i}$ is the activation energy, $R$ the universal gas constant, $t$ is time and $T$ the temperature. The total rate of evolution of volatiles is then given by summation of Eq. (1) as:

$$
\frac{\mathrm{d} m}{\mathrm{~d} t}=\sum_{i} \frac{\mathrm{d} m_{i}}{\mathrm{~d} t}=\sum_{i}-A_{0 i} \mathrm{e}^{\frac{-E_{i}}{R T}}\left(M_{i}-m_{i}\right) .
$$

Using Eq. (1), we have:

$$
\frac{\mathrm{d} m_{i}}{\left(M_{i}-m_{i}\right)}=-k_{i} \mathrm{~d} t
$$

After integrating Eq. (4), we get: 


$$
\frac{\left(M_{i}-m_{i}\right)}{M_{i}}=\mathrm{e}^{\int_{T_{0}}^{T} \frac{-k_{i} \mathrm{~d} T}{\theta}}
$$

Now suppose that the total fraction $M_{i}$ of the total effectivemass $M_{0}$ evolvedbyreactionswith activation energies between $E_{i}-\frac{\Delta E_{i}}{2}$ and $E_{i}+\frac{\Delta E_{i}}{2}$ so that:

$$
\begin{gathered}
M_{i}=M_{0} x \phi\left(E_{i}\right) \Delta E_{i}, \\
\frac{M_{t}}{M_{0}}=X_{\text {Calculated }}=\sum_{i} X_{i}=\sum_{i} \frac{\left(M_{i}-m_{i}\right)}{M_{i}},
\end{gathered}
$$

where $M_{t}$ is massofbiomassatinstanttimetand $M_{0}$ is total effective mass.

Using Eq. (5) and(6), we get

$$
X_{\text {Calculated }}=\sum_{i} X_{i}=\sum_{i} \phi\left(E_{i}\right) \Delta E_{i} x \mathrm{e}^{\int_{T_{0}}^{T} \frac{-k_{i} \mathrm{~d} T}{\theta}} .
$$

If the total number of parallel reactions $i$ is large enough, Eq. (7) can be rewritten as:

$$
X_{\text {Calculated }}=\int_{T_{0}}^{T} \phi(E) \Delta E x \mathrm{e}^{\int_{T_{0}}^{T} \frac{-k_{i} \mathrm{~d} T}{\theta}},
$$

where

$$
T=T_{0}+\theta(t)
$$

In 1974, Anthony [18] suggested value of $f(E)$ with the help of Gaussian distribution function by involving mean activation energy and standard deviation $(\sigma)$, which can be expressed as:

$$
\begin{gathered}
f(E)=\frac{1}{\sqrt{2 \pi \sigma}} \mathrm{e}^{-\frac{\left(E-E_{0}\right)^{2}}{2 \sigma^{2}}}, \\
X_{\text {Calculated }}=\int_{T_{0}}^{T} \frac{1}{\sqrt{2 \pi \sigma}} \mathrm{e}^{-\frac{\left(E-E_{0}\right)^{2}}{2 \sigma^{2}}} \mathrm{~d} E \mathrm{e}^{\int_{T_{0}}^{T} \frac{-k_{i} \mathrm{~d} T}{\theta}},
\end{gathered}
$$

or

$$
X_{\text {Calculated }}=\int_{0}^{\infty} \frac{1}{\sigma \sqrt{2 \pi}} \mathrm{e}^{\left(-\frac{\left(E-E_{0}\right)^{2}}{2 \sigma^{2}}+\int_{T_{0}}^{T} \frac{-k_{i} \mathrm{~d} T}{\theta}\right)} \mathrm{d} E \text {. }
$$

The remaining mass fraction can be defined as:

$$
X_{\text {experiment }}=\frac{\left(M_{t}-M_{\mathrm{f}}\right)}{\left(M_{0}-M_{\mathrm{f}}\right)}
$$

The significant role of Eq. (11) is to determine the initial distribution of volatiles $f(E)$, the frequency or pre-exponential factors $A_{0}(E)$ and thereafter estimate the resulting time dependence of the decomposed fraction. For finding solution, frequency factor, mean activation energy, and the variance are optimized to reach a minimum of Eq. (13): 


$$
\operatorname{MSE}(\text { root mean squared error })=\sqrt{\sum_{i=1}^{N} \frac{\left(X_{\text {experiment }}-X_{\text {Calculated }}\right)^{2}}{N}} .
$$

The double exponential integrand in Eq. (11) is:

$$
\operatorname{dexp}=\exp \left(-\int_{T_{0}}^{T}\left(\frac{A_{0}}{\theta} \mathrm{e}^{-\frac{E}{R T}}\right)\right) \mathrm{d} T
$$

The term inside the exponent is approximated by applying Laplace methods, where in the parameter $E / R T$ is considered to be large.

$$
\operatorname{dexp}=\exp \left(-\int_{T_{0}}^{T}\left(\frac{A_{0}}{\theta} \mathrm{e}^{-\frac{E}{R T}}\right)\right) \mathrm{d} T \sim \exp \left(\frac{-A_{0} R\left(T-T_{0}\right)^{2}}{\theta^{2} E} \mathrm{e}^{-\frac{E}{R T}}\right) \text { as } \frac{\theta^{2} E}{-A_{0} R\left(T-T_{0}\right)^{2}} \rightarrow \infty .
$$

The Eq. (15) can be expressed in the form:

$$
\operatorname{dexp}=\exp \left(-\exp \left(\frac{E_{\mathrm{s}}-E}{E_{\mathrm{w}}}\right)\right)
$$

where the function increases rapidly from zero to one as $E$ increases, over range of size $E_{\mathrm{w}}$ around $E_{\mathrm{s}}$, and this can be approximated as follows:

$$
g(E)=\left(\frac{E_{\mathrm{s}}-E}{E_{\mathrm{w}}}\right)
$$

where

$$
g(E)=-\frac{E}{R T}+\ln \left(\frac{A_{0} R\left(T-T_{0}\right)^{2}}{\theta^{2} E}\right)
$$

As only the behaviour at the neighborhood of $E_{\mathrm{s}}$ is of interest, the function $g(E)$ is expanded around $E_{\mathrm{s}}$ by Taylor series as:

$$
g(E)=g\left(E_{\mathrm{s}}\right)+\left(E-E_{\mathrm{S}}\right) g^{\prime}(E)+\cdots
$$

Using Eq. (16) and (17), $E_{\mathrm{s}}$ and $E_{\mathrm{w}}$ are chosen so that

$$
g\left(E_{\mathrm{S}}\right)=0 \text { and } g^{\prime}\left(E_{\mathrm{S}}\right)=-\frac{1}{E_{\mathrm{w}}}
$$

Solving these gives

$$
E_{\mathrm{s}}=\operatorname{RTY}\left(A_{0} \frac{\left(T-T_{0}\right)}{\theta}\right)
$$

and

$$
E_{\mathrm{w}}=\frac{R T E_{\mathrm{s}}}{R T+E_{\mathrm{s}}}
$$

where $Y(x)$ represents Lambert $W$ function defined to be one real root of the equation [22].

For other cases, Lambert $W$ function can be expressed as: 


$$
\begin{gathered}
Y e^{Y}=x, \\
Y \sim x-x^{2}, \quad x \ll 1, \\
Y \sim \ln \left(\frac{x}{\ln \left(\frac{x}{\ln x}\right)}\right), \quad 1 \ll x .
\end{gathered}
$$

Double exponential term (dexp) has attribute of smoothed step-function that varies from zero to one with step size of $E_{\mathrm{w}}$. In Eq. (11), dexp is multiplied by the initial distribution $f(E)$. After simplification of Eq. (11), we get:

$$
X_{\text {Calculated }}=\frac{1}{\sigma \sqrt{2 \pi}} \int_{0}^{\infty} \exp (h(E)) \mathrm{d} E,
$$

where $h(E)$ is defined as:

$$
h(E)=-\exp \left(\frac{E_{\mathrm{s}}-E}{E_{\mathrm{w}}}\right)-\frac{\left(E-E_{0}\right)^{2}}{2 \sigma^{2}} .
$$

Energy is now rescaled as $y=\frac{E}{E_{0}}$, so that integrand becomes

$$
\begin{gathered}
X_{\text {Calculated }}=\sqrt{\frac{\alpha}{\pi}} \int_{0}^{\infty} \exp \left(-\exp \left(\frac{y_{\mathrm{s}}-y}{y_{\mathrm{w}}}\right)-\alpha(y-1)^{2}\right) \mathrm{dy}, \\
h(y)=-\exp \left(\frac{y_{\mathrm{s}}-y}{y_{\mathrm{w}}}\right)-\alpha(y-1)^{2},
\end{gathered}
$$

where the constant parameter, $\alpha=\frac{E_{0}^{2}}{2 \sigma^{2}}$. Note that in practice $1<<\alpha$.

For linear ramping temperature $T=T_{0}+\theta(t)$, we have:

$$
y_{\mathrm{s}}=\frac{R T}{E_{0} A_{0}} Y(\tau), y_{\mathrm{w}}=\frac{y_{\mathrm{s}}}{(1+Y(\tau))},
$$

where $Y(\tau)$ is Lambert $W$ function and time has been rescaled as $\tau=A_{0} t$.

We have discussed both of cases of Gaussian distribution to find the best distribution case for the large and concentrated data points $(N>6000)$. Vargheyi [23] used numerical method with the help of Gauss-Hermite quadrature formula to solve DAEM. They gave rescaling factor of $1 / 2$ by introducing variable $\mu$.

\subsection{The Wide Distribution Case}

For wide distribution case, the limited $y_{\mathrm{w}} \alpha^{1 / 2} \rightarrow 0$ is taken. Within limit the double exponential term in Eq. (14) converge between range of $(0,1)$. This is approximated with help of step function $U$ as previously approximated [14], [15], [24], [25] can be given by:

$$
U\left(y-y_{\mathrm{s}}\right)=\left\{\begin{array}{l}
0, y<y_{\mathrm{s}} \\
1, y_{\mathrm{s}} \leq y
\end{array}\right.
$$


Eq. (21) can be modified with help of error and step functions and expressed as:

$$
\begin{aligned}
& X_{\text {Calculated }}=\sqrt{\frac{\alpha}{\pi}} \int_{0}^{y_{\mathrm{s}}}\left[\exp \left(-\exp \left(\frac{y_{\mathrm{s}}-y}{y_{w}}\right)\right)-U\left(y-y_{\mathrm{s}}\right)\right]\left(\exp \left(-\alpha(y-1)^{2}\right)\right) \mathrm{d} y \\
& +\sqrt{\frac{\alpha}{\pi}} \int_{y_{\mathrm{s}}}^{\infty} \exp \left(-\alpha(y-1)^{2}\right) \mathrm{d} y .
\end{aligned}
$$

The second integral is a complementary error function or normal distribution and can be computed easily. The term $\exp \left(-\alpha(y-1)^{2}\right)$ is very small everywhere except in neighbourhood of size $y_{\mathrm{w}}$ around the point $y=y_{\mathrm{s}}$. Applying Taylor series about $y=y_{\mathrm{s}}$, this integrand can therefore be approximated as:

$$
\begin{aligned}
& \text { L.H.S }=\sqrt{\frac{\alpha}{\pi}} \int_{0}^{y_{\mathrm{s}}}\left[\exp \left(-\exp \left(\frac{y_{\mathrm{s}}-y}{y_{\mathrm{w}}}\right)\right)-U\left(y-y_{\mathrm{s}}\right)\right]\left(1+\left(y-y_{\mathrm{s}}\right) 2 \alpha\left(y_{\mathrm{s}}-1\right)\right. \\
& +\exp \left(-\alpha\left(y_{\mathrm{s}}-1\right)^{2}\right) \mathrm{d} y+\sqrt{\frac{\alpha}{\pi}} \int_{y_{\mathrm{s}}}^{\infty} \exp \left(-\alpha(y-1)^{2}\right) \mathrm{d} y .
\end{aligned}
$$

Each of the integrals is obtained from a term in Taylor series and can be integrated separately to yield Eq. (23) as:

$$
\begin{gathered}
X_{\text {Calculated }}=\frac{1}{2} \operatorname{erfc}\left(\left(y_{\mathrm{s}}-1\right) \sqrt{\alpha}\right)+\quad \sqrt{\frac{\alpha}{\pi}} y_{\mathrm{w}} \exp \left(-\alpha\left(y_{\mathrm{s}}-1\right)^{2}\left[B_{0}-2 \alpha y_{\mathrm{w}}\left(y_{\mathrm{s}}-1\right) B_{1}\right.\right. \\
\left.+\alpha y_{\mathrm{w}}{ }^{2}\left[2 \alpha\left(y_{\mathrm{s}}-1\right)^{2}-1\right] B_{2}+\frac{2}{3} y_{\mathrm{w}}{ }^{3} \alpha^{2}\left[2\left(y_{\mathrm{s}}-1\right)+2 \alpha\left(y_{\mathrm{s}}-1\right)^{3}+1\right] B_{3}\right],
\end{gathered}
$$

where the remaining integral can be estimated by:

$$
B_{i}=\int_{-\infty}^{\infty}\left(y-y_{\mathrm{s}}\right)^{i}\left(\exp \left(-\exp \left(-\left(y-y_{\mathrm{s}}\right)\right)-U\left(y-y_{\mathrm{s}}\right)\right) \mathrm{d} y, \quad i=0,1,2,3, \ldots .\right.
$$

This expansion is valid only when $\alpha y_{\mathrm{w}}\left(y_{\mathrm{s}}-1\right)<<1$, further terms can be found out for improving accuracy of the Eq. (26).

\subsection{The Narrow Distribution Case}

The limit applied in case of narrow distribution satisfy $\sigma<<\sqrt{2} R T_{\mathrm{C}}$, where $T_{\mathrm{C}}$ is the temperature of point of inflection in a plot of $X_{\text {Calculated }}$ vs $T$. By involving time dependent maximum which proceeds in a same manner as time. The yield result that is more robust and more accurate over a wider range of operating parameters.

The maxima of Eq. (22), $y_{\mathrm{m}}$ of $y$ is sought, where the function $h(y)$ tends to be at an extremum, by putting $h^{\prime}(y)=0$. Hence,

$$
h^{\prime}(y)=\frac{\exp \left(\frac{\left(y_{\mathrm{s}}-y\right)}{y_{\mathrm{w}}}\right)}{y_{\mathrm{w}}}-2 \alpha(y-1)
$$

or 


$$
\exp \frac{\left(y_{\mathrm{s}}-y_{\mathrm{m}}\right)}{y_{\mathrm{w}}}=2 \alpha y_{\mathrm{w}}\left(y_{\mathrm{m}}-1\right)
$$

The solution is given by:

$$
y_{\mathrm{m}}=1+y_{\mathrm{w}} Y\left(\frac{1}{2 \alpha y_{\mathrm{w}}^{2}} \exp \left(\frac{y_{\mathrm{s}}-1}{y_{\mathrm{w}}}\right)\right)
$$

A Taylor series expansion of $h(y)$ about $y_{\mathrm{m}}$ provided a solution of Eq. (21) is given by:

$$
h(y) \sim h\left(\mathrm{y}_{\mathrm{m}}\right)+\frac{h^{\prime \prime}\left(y_{\mathrm{m}}\right)\left(y-y_{\mathrm{m}}\right)^{2}}{2 !}+O\left(\mathrm{~h}_{4}\right) .
$$

After solving, we get:

$$
X_{\text {Calculated(narrow) }}=\frac{\exp \left[-\alpha\left(y_{\mathrm{m}}-1\right)\left(y_{\mathrm{m}}+2 y_{\mathrm{w}}-1\right)\right]}{\sqrt{1+\frac{\mathrm{ym}_{\mathrm{m}}-1}{y_{\mathrm{w}}}}} .
$$

Computation of Eq. (23),(26) and (28) were done with help of algorithm created in MATLAB. The calculating procedure of DAEM kinetic parameter is shown in the block diagram of optimization scheme in Fig. 1.

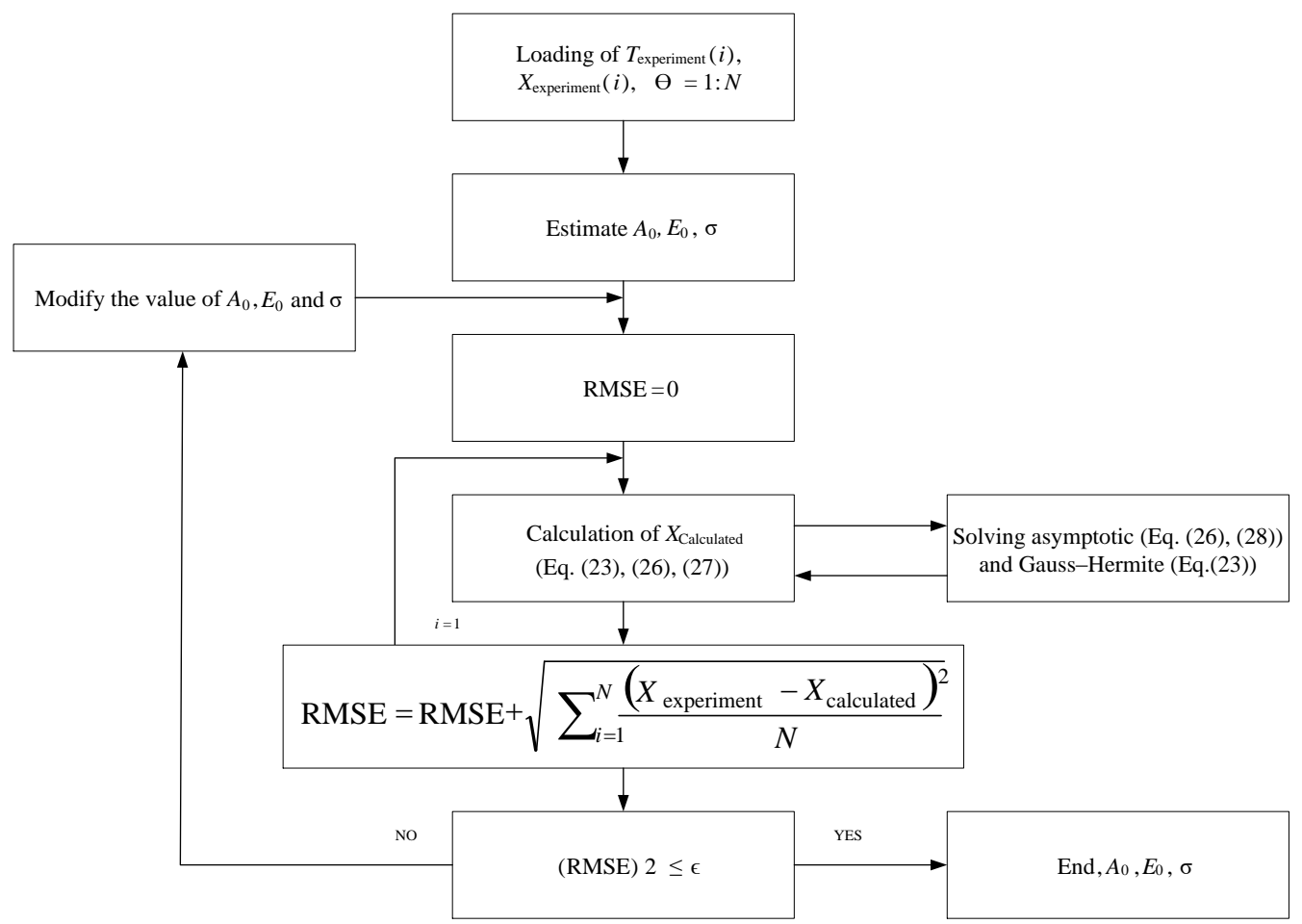

Fig.1. DAEM kinetic parameters optimization block scheme. 


\section{RESUlt AND DiscuSSIONS}

\subsection{Thermal Decomposition of Forest Waste (Pine Needles)}

The thermogravimetric (TG) and differential thermogravimetric (DTG) curves of pine needles obtained at heating rate of $10^{\circ} \mathrm{C} / \mathrm{min}$ are plotted in Fig. 2 (a, b). It can be clearly seen that bonded water and air moisture evaporated first. The end of drying is at about $77{ }^{\circ} \mathrm{C}$. However, for wood, it is around $160{ }^{\circ} \mathrm{C}$. The process of pyrolysis of pine needles begins above this temperature. As Fig. 2(b) shows decomposition of wood, the first local minimum on DTG wood decomposition curve corresponds to the time when the maximum decomposition rate of hemicelluloses is reached. Global minimum on the DTG wood decomposition curve corresponds to the time when maximum decomposition rate of cellulose is reached. Thermal decomposition of lignin doesn't have significant role as the other two compounds and degradation of lignin takes place after cellulose which can be seen by third peak in Fig. 2(b). However, lignin decomposition enhances global minimum and hence can be seen as a contribution of lignin decomposition since at these temperatures, both hemicellulose and cellulose are already decomposed.

The peak complexity is more visible at higher ramping rates due to the relatively high content of hemicelluloses degrades at lower temperature as cellulose. The mass loss rate of cellulose increased greatly with temperature and reached its maximum value at about $327{ }^{\circ} \mathrm{C}$, whereas it was about $277^{\circ} \mathrm{C}$ and $397^{\circ} \mathrm{C}$ for hemicelluloses and lignin contents respectively. As the temperature increased over $397^{\circ} \mathrm{C}$, rate of mass loss lower until reached the final temperature. The range of temperature is not fixed for a particular material, which is subjected to analyse. As ramping rate increases above $10^{\circ} \mathrm{C} / \mathrm{min}$, both $\mathrm{TG}$ and $\mathrm{DTG}$ curves exhibit a shift in global minimum and local minimum within the same temperature range. Such thermal hysteresis was explained by Bilbao et al. [26]. According to their view point, this is due to the fact that the heating rate affects the temperature gradient between inner and outer parts of the samples and hence temperature gradient varies directly to ramping and mass loss rates. As compare to cellulose and lignin, variation in hemicelluloses is not shown significant changes by increasing the ramp rate, so it can be concluded that the thermal decomposition process of hemicelluose proceeds into two step reactions. Such behavior had been discussed by Varhegyi et al. [23], and they attempted to describe the double peaks observed by models based on successive reactions.

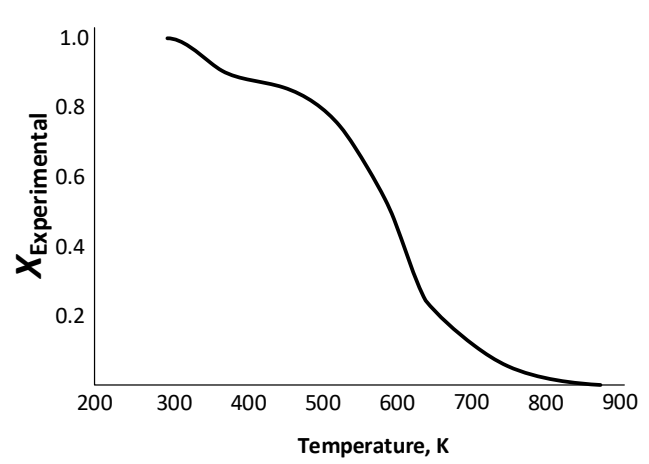

(a)

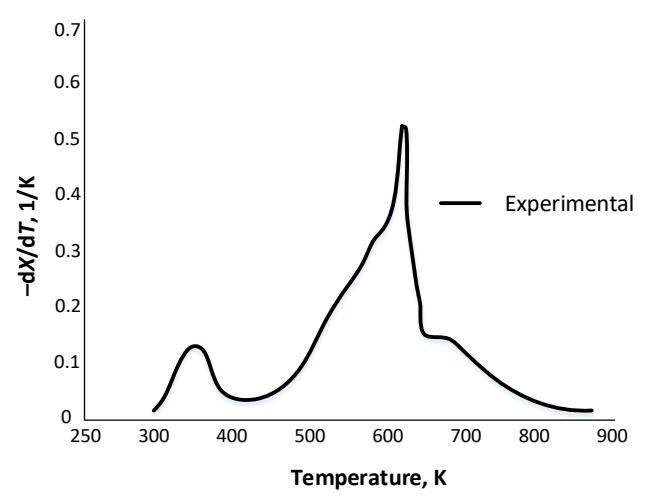

(b)

Fig. 2. Experimental TGA (a) and DTG (b) curves for pyrolysis of pine needles at the heating rate of $10{ }^{\circ} \mathrm{C} / \mathrm{min}$. 


\subsection{Kinetics of Thermal Decomposition}

Asymptotic simplification of Gauss distribution as based equation was used for generating a result with the mean activation energy $E_{0}$ and variance $\sigma_{2}$. For comparing and validating our results, we compared our asymptotic Eq. (26) with narrow distribution case of Gauss integral equation (Mc Guinness et al.) and Gauss-Hermite quadrature method [23]. The usage of DAEM for knowing the predicated thermal decomposition of various materials is to only compare mass fraction $(X)$ integral as a function of temperature with the known value [27]. Another important term is the differential change of the remaining mass fraction as a function of temperature. In comparison with the integral decomposition curve, the differential curve has the better convergence of roots and lesser deviations, which cannot be seen in the integral dependence. Asymptotic equation was found to be satisfactory for large number of concentrated data $(6000<N)$ points. With increasing data points $\mathrm{N}$, numerical solutions of numerical method had more deviation than that of asymptotic method. However, asymptotic equations converge very slowly with time and hence require large number of iterations. Initial distribution activation energy model comprises two different functions: Gaussian and Arrhenius, which is unable to give smooth and accurate results, as initial distribution $f(E)$ and the pre-exponential factors $A_{0}(E)$ are highly correlated so some simplification was made by assuming the same value of pre frequency factors for all the reactions. Mathematically, the approximate solution of pyrolysis by DAEM can be described as in Eq. (26). The kinetic parameters of pine needles pyrolysis decomposition obtained by DAEM are shown in Table 2. From the integraldependence of pine needles decomposition (Fig. 3(a)), simulated result of DAEM appears to describe basic trends of the pyrolysis process. However, inaccuracies of results have been seen when comparing the differential experimental data with simulated data (Fig. 3(b)). The diversion of roots of equation show the mathematical model is unable to simulate more than one maxima, but in reality, there are three global maximums. So, differential dependence of mass fractions is applicable to individual compounds of mixture since they are not expected to be a mixture of several compounds. However, a relatively wide distribution case was found to be more suitable for materials which comprise of different volatile components. Hence, we attempted another mathematical calculation for describing decomposition of pine needles compounds, such as hemicellulose, cellulose and lignin by DAEM, as they are not mixture of several other compounds.

A comparison of experimental and simulated integral curves of the thermal decomposition of pine needles main compounds at a heating rate of $283 \mathrm{~K} / \mathrm{min}$ is shown in Fig. 4. As in figure, it seems that DAEM can describe the decomposition curve without much deviation. The point of inflection has been observed at the end of the decomposition process above $650 \mathrm{~K}$. As discussed above, all deviations can be seen at comparison of the differential correlation, shown in Fig. 4(a). Inaccuracies in the description of the inflection point and the end of the process at integral curves are clearly seen since after re-evaluation to differential correlation. Therefore, the differential curves are more significant from the point of modeling precision view. Mathematical correlation of the pyrolysis process by the distributed activation energy model and the model precision can be affected by several factors such as number of points dividing the temperature interval, width of activation energies interval $\left(E_{\mathrm{w}}\right)$ and the number of experimental data points. Numerical methods (Gauss-Hermite) varies rapidly with small number of large interval and doesn't converge to analytical solution, so it is very important to select the most representative range of experimental data. The drawback of numerical method has been overcome by asymptotic method that varies slowly within broad range. Functionality of DAEM is to describe also the parts of the process where there are any mass changes. In addition, the results have been significantly influenced by the objective functions of this model as it compares integral values unlike other methods where differential values are used. The derived optimized parameters obtained after analysis of data 
points from DAEM for hemicelluloses, cellulose and lignin are enlisted in Table 3. The values of obtained activation energies and frequency factors fall into interval reported in literature [27], [28].

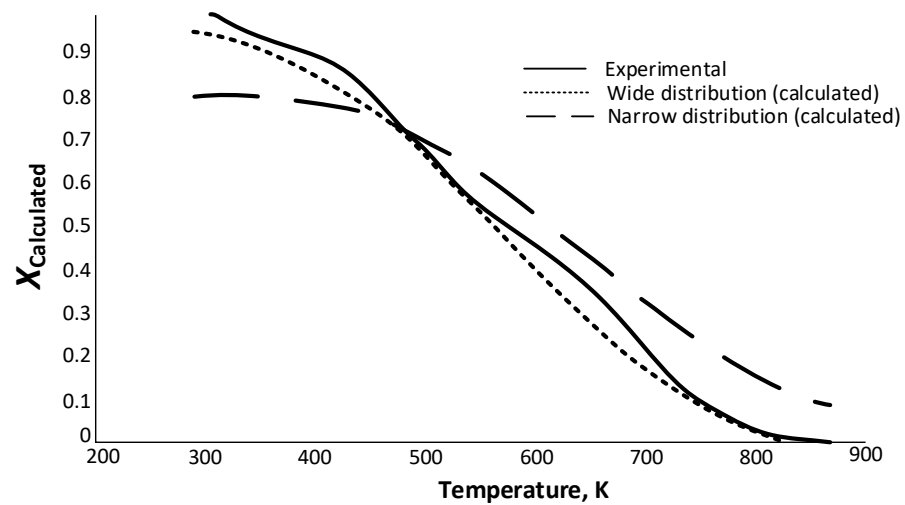

(a)

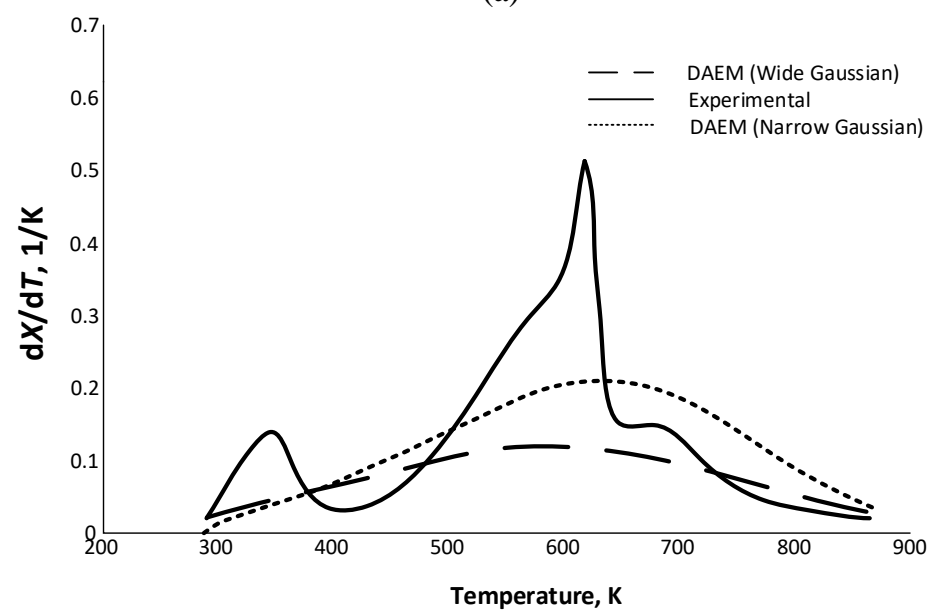

(b)

Fig. 3. Pyrolysis decomposition of pine needles at $283 \mathrm{~K} / \mathrm{min}$ (a) integral; (b) differential (experimental, DAEM (Narrow and Wide distribution cases).

TABLE 2. KINETIC PARAMETERS OBTAINED BY DAEM AND ERROR IN VARIOUS METHODS FOR PINE NEEDLES DECOMPOSITION

\begin{tabular}{lllllll}
\hline Sample & Technique & Case & $\mathbf{\sigma , ~ k J / m o l}$ & $\boldsymbol{E}_{\mathbf{0}}, \mathbf{k J} / \mathbf{m o l}$ & $\boldsymbol{A}_{\mathbf{0}}, \mathbf{s}^{-\mathbf{1}}$ & $\mathbf{\epsilon}$ \\
\hline & $\begin{array}{l}\text { Asymptotic } \\
\text { Method }\end{array}$ & $\begin{array}{l}\text { Wide } \\
\text { distribution } \\
\text { (Gaussian) }\end{array}$ & 62.7793 & 107.1901 & $2.9315 \times 10^{18}$ & $1.0778 \times 10^{-8}$ \\
$\begin{array}{l}\text { Pine } \\
\text { needles }\end{array}$ & & $\begin{array}{l}\text { Narrow } \\
\text { distribution } \\
\text { (Gaussian) }\end{array}$ & 1.2537 & 1.5904 & $5.76 \times 10^{-4}$ & $1.1 \times 10^{-2}$ \\
& $\begin{array}{l}\text { Numerical } \\
\text { Method }\end{array}$ & $\begin{array}{l}\text { Gauss-Hermite } \\
\text { quadrature }\end{array}$ & 26.8866 & 45.0464 & $1.1235 \times 10^{6}$ & $19 \times 10^{2}$ \\
\hline
\end{tabular}



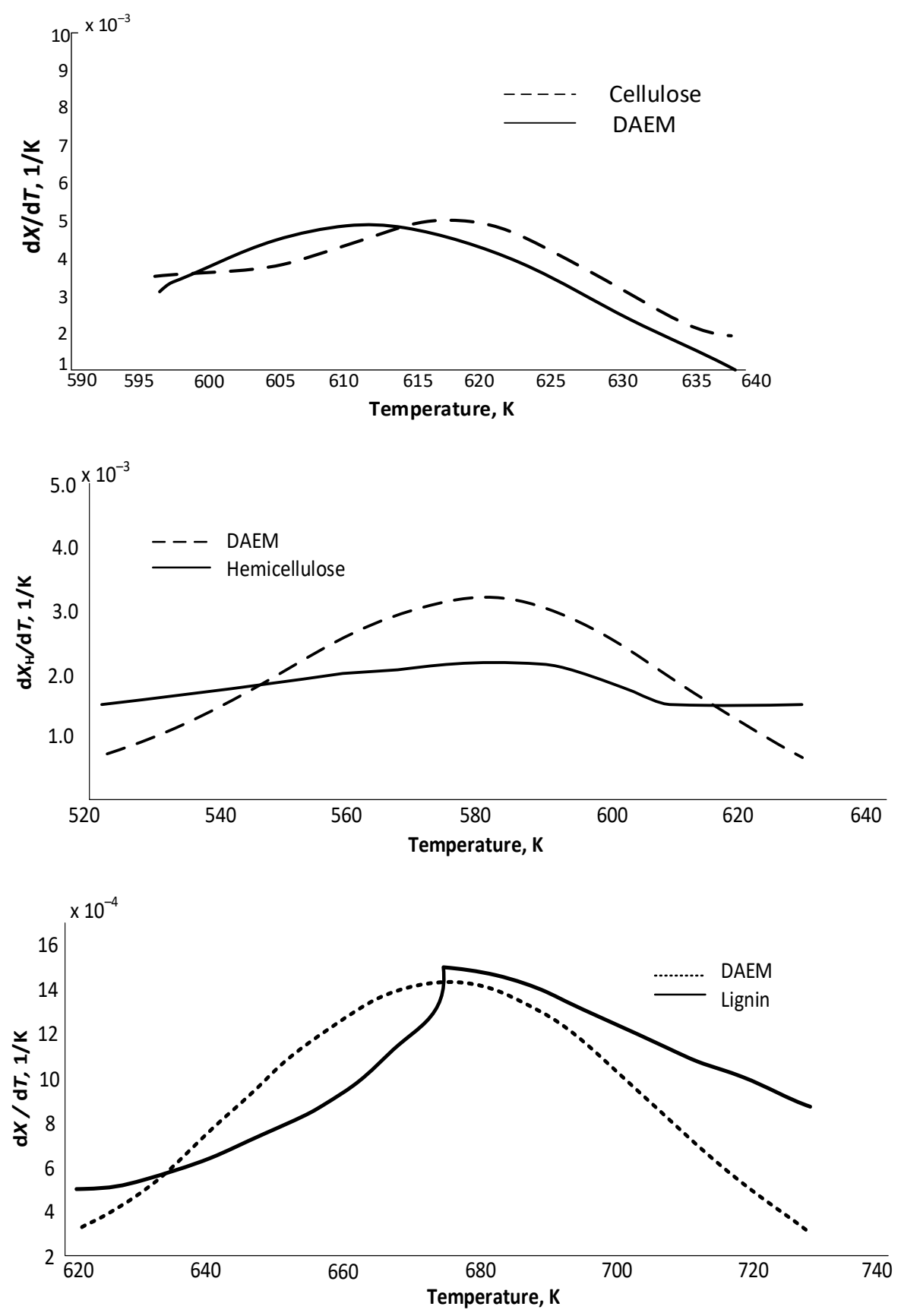

(a) 

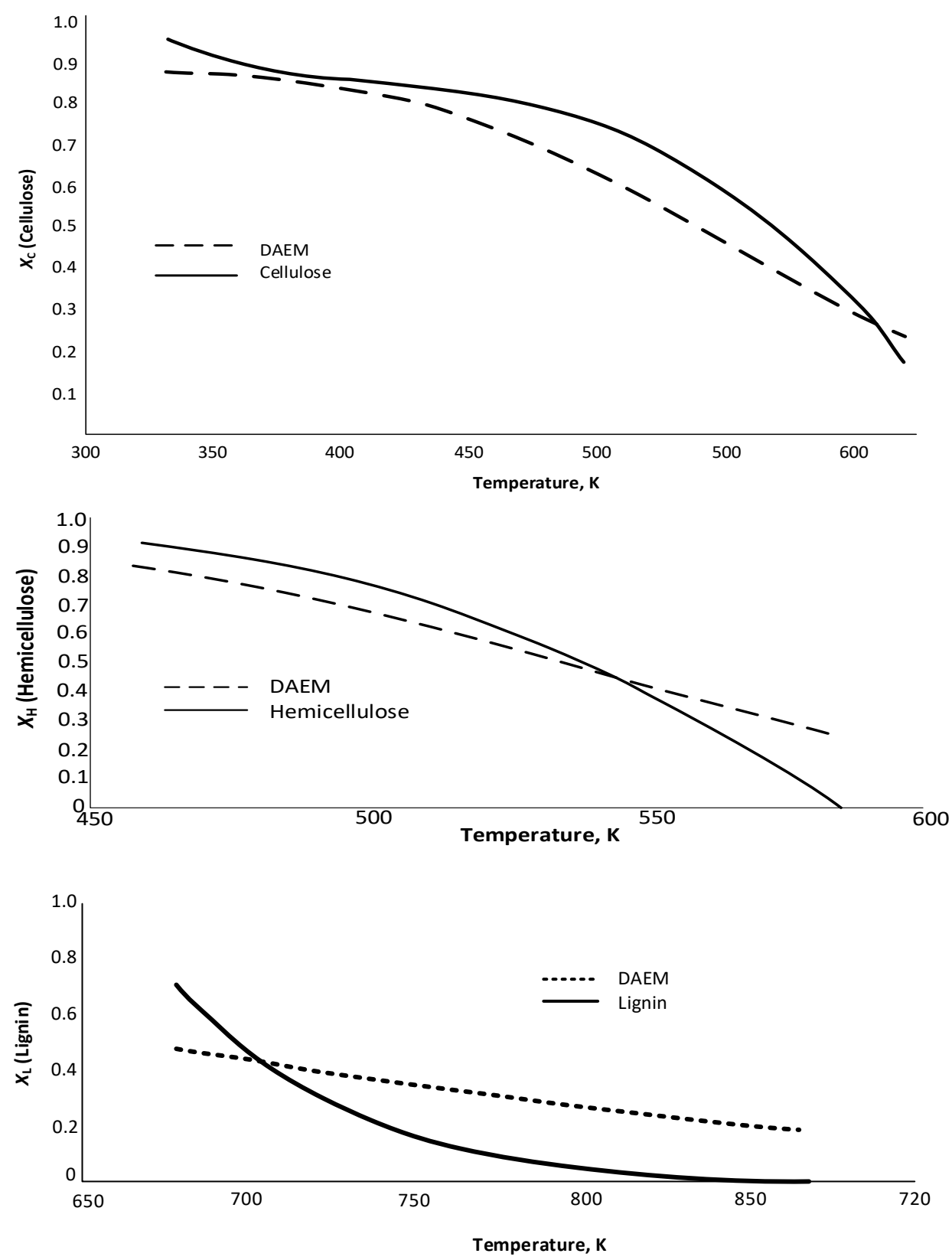

(b)

Fig.4. Pyrolysis decomposition of cellulose, hemicelluloses and lignin at $283 \mathrm{~K} / \mathrm{min}$ (a) differential; (b) integral respectively. 
TABle 3. Kinetic PARAMETERS OBTAINED By DAEM AND ERROR FOR CELlULOSE, HEMICELLULOSES AND LIGNIN

\begin{tabular}{lllll}
\hline Compounds & $\boldsymbol{\sigma}, \mathbf{k J} / \mathbf{m o l}$ & $\boldsymbol{E}_{\mathbf{0}}, \mathbf{k J} / \mathbf{m o l}$ & $\boldsymbol{A}_{\mathbf{0}}, \mathbf{s}^{-\mathbf{1}}$ & $\boldsymbol{\epsilon}$ \\
\hline Cellulose & 55.1530 & 152.0627 & $1.0087 \times 10^{34}$ & $7.5335 \times 10^{-8}$ \\
Hemicellulose & 20.6981 & 133.5493 & $2.9815 \times 10^{31}$ & $1.849 \times 10^{-7}$ \\
Lignin & 4.83495 & 57.9053 & $2.9315 \times 10^{7}$ & $7.075 \times 10^{-8}$ \\
\hline
\end{tabular}

In order to verify whether the evaluated kinetic parameters were suitable or not for describing only the curve for which they were optimized, a comparison of calculated and experimental data of cellulose decomposition at two different heating rates, $283 \mathrm{~K} / \mathrm{min}$ and $293 \mathrm{~K} / \mathrm{min}$, where the kinetic parameters were obtained by optimization at $283 \mathrm{~K} / \mathrm{min}$ were used as shown in Fig. 5 . In order to simulate correctly the differential curves, the mathematical modification was done for describing pyrolysis decomposition of pine needles, which is a linear combination of three single asymptotic Eq. (29) for DAEM.

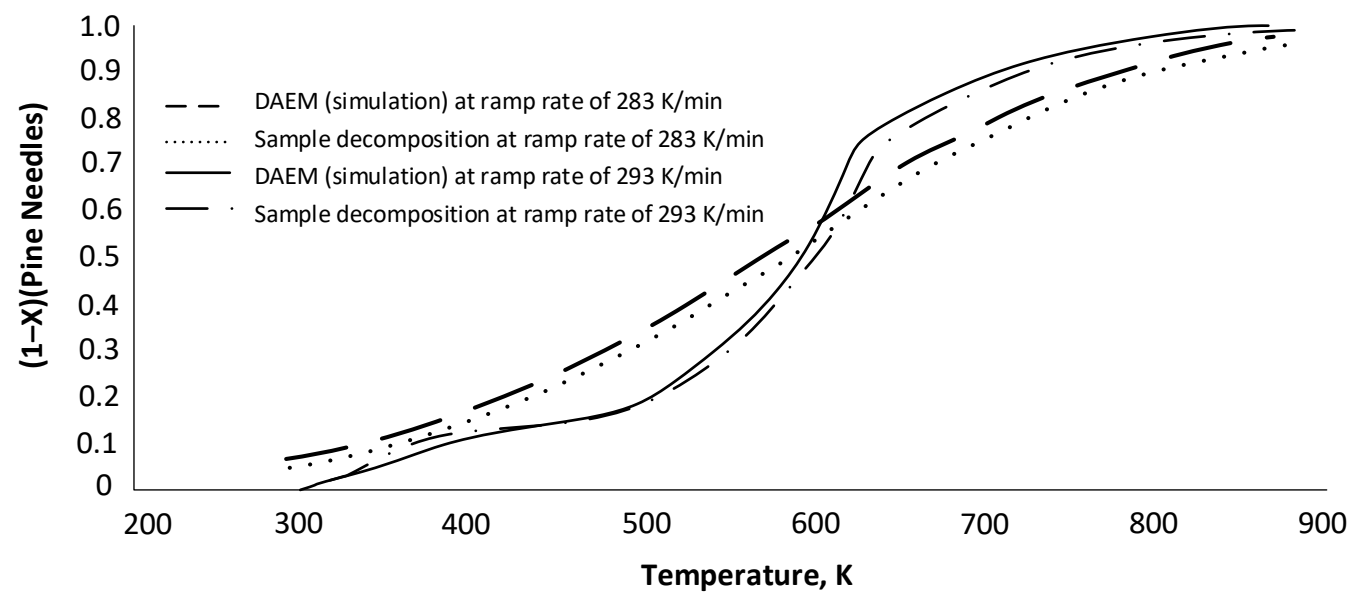

Fig. 5.Verification of optimized kinetic parameters applicability for different ramp rates: $283 \mathrm{~K} / \mathrm{min}$ and $293 \mathrm{~K} / \mathrm{min}$.

$$
\begin{gathered}
X_{\text {Calculated }}=\frac{1}{2} \operatorname{erfc}\left(\left(y_{\mathrm{sC}}-1\right) \sqrt{\alpha}\right)+\sqrt{\frac{\alpha}{\pi}} y_{\mathrm{wC}} \exp \left(-\alpha\left(y_{\mathrm{sC}}-1\right)^{2}\left[B_{0}-2 \alpha y_{\mathrm{wC}}\left(y_{\mathrm{sC}}-1\right) B_{1}\right.\right. \\
+\alpha y_{w}{ }^{2}\left\{2 \alpha\left(y_{\mathrm{sC}}-1\right)^{2}-1\right\} B_{2}+\frac{2}{3} y_{\mathrm{wC}}{ }^{2} \alpha^{2}\left\{2\left(y_{\mathrm{sC}}-1\right)+2 \alpha\left(y_{\mathrm{sC}}-1\right)^{3}+\right. \\
\left.1\} B_{3}\right]+\frac{1}{2} \operatorname{erfc}\left(\left(y_{\mathrm{sH}}-1\right) \sqrt{\alpha}\right)+\sqrt{\frac{\alpha}{\pi}} y_{\mathrm{wH}} \exp \left(-\alpha\left(y_{\mathrm{sH}}-1\right)^{2}\left[B_{0}-2 \alpha y_{\mathrm{wH}}\left(y_{\mathrm{sH}}-1\right) B_{1}\right.\right. \\
\left.+\alpha y_{\mathrm{w}}{ }^{2}\left\{2 \alpha\left(y_{\mathrm{sH}}-1\right)^{2}-1\right\} B_{2}+\frac{2}{3} y_{\mathrm{wH}}{ }^{3} \alpha^{2}\left\{2\left(y_{\mathrm{sH}}-1\right)+2 \alpha\left(y_{\mathrm{sH}}-1\right)^{3}+1\right\} B_{3}\right] \\
+\frac{1}{2} \operatorname{erfc}\left(\left(y_{\mathrm{sL}}-1\right) \sqrt{\alpha}\right)+\sqrt{\frac{\alpha}{\pi}} y_{\mathrm{wL}} \exp \left(-\alpha\left(y_{\mathrm{sC}}-1\right)^{2}\left[B_{0}-2 \alpha y_{\mathrm{wL}}\left(y_{\mathrm{sL}}-1\right) B_{1}\right.\right. \\
\left.+\alpha y_{\mathrm{w}}{ }^{2}\left\{2 \alpha\left(y_{\mathrm{sL}}-1\right)^{2}-1\right\} B_{2}+\frac{2}{3} y_{\mathrm{wC}}{ }^{3} \alpha^{2}\left\{2\left(y_{\mathrm{sL}}-1\right)+2 \alpha\left(y_{\mathrm{sL}}-1\right)^{3}+1\right\} B_{3}\right],
\end{gathered}
$$


where the subscript mean the same as those in Eq. (28), but each single DAEM represents one of the three components ( $\mathrm{H}$ - hemicellulose, $\mathrm{C}$ - cellulose, $\mathrm{L}$ - lignin).

Eq. (29) has three parts, which express the mathematical expression of pyrolysis decomposition of pine needles. Procedure of performing optimization by Eq. (13) is similar to the single DAEM. A comparison of pine needles pyrolysis decomposition and data obtained by mathematical simulation using Eq. (29) is shown in Fig.6. Results obtained from Eq. (29) are closely fitted to the compared experimental data.

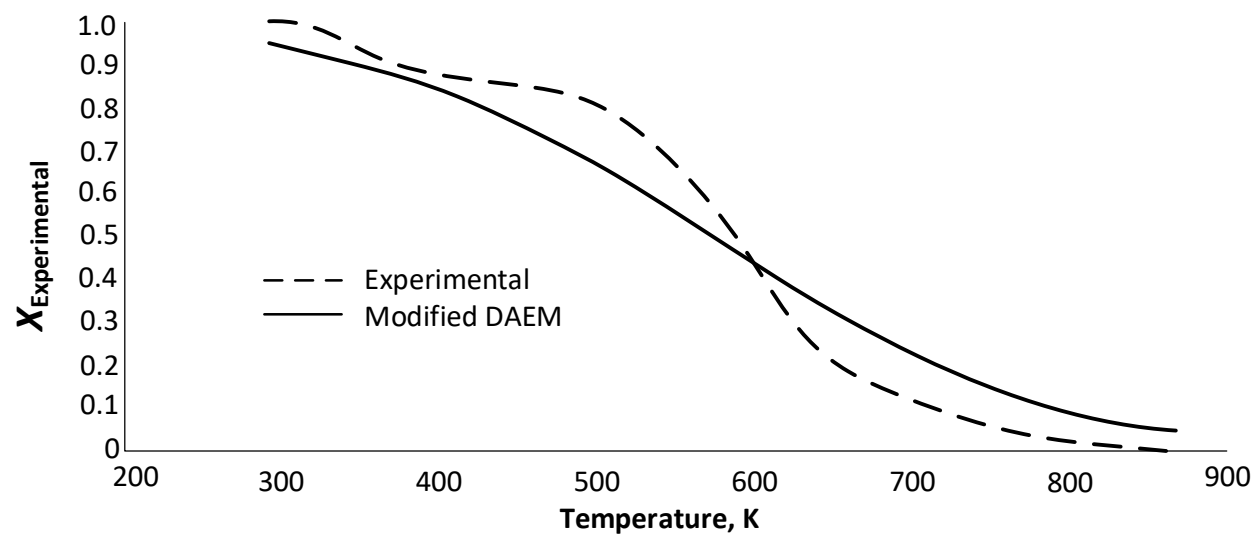

(a)

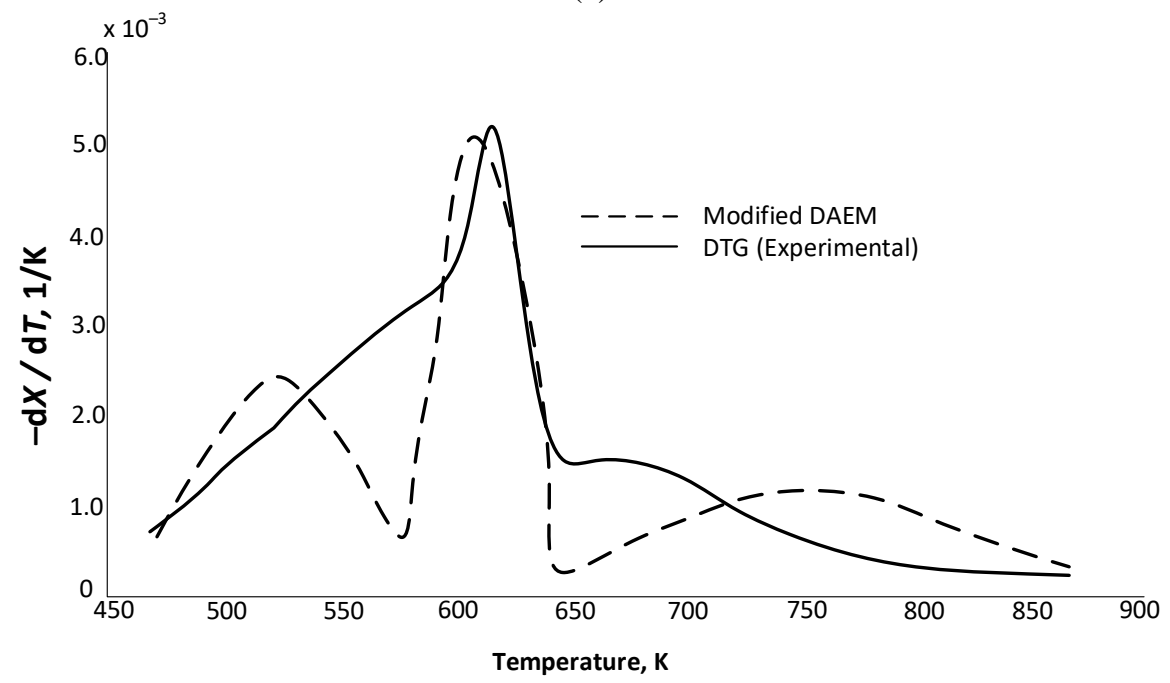

(b)

Fig. 6. Mathematical description of pine needles pyrolysis decomposition at $283 \mathrm{~K} / \mathrm{min}$ by modified DAEM (a) integral; (b) differential.

The modified model is capable to generate better results to describe the changes of mass loss with temperature, yet there are some visible deviations in the differential curve. Although in case of integral curve it is perfectly correlated with experimental data. After invoking it for the 
differential data, it can be seen that the model cannot exactly converge at starting and the end of the decomposition process. Results obtained by using modified DAEM seem to be closely fitted to the experimental data points that of single DAEM. However, increasing number of terms (as activation energies) from one to three do not serve main purpose of DAEM. Evaluated parameters for modified DAEM are shown in Table 4. The lowest value of variance represents decomposition of cellulose in differential form and that is described by one narrow peak [29]. All values of variance in each simulation are large, implying that the distribution of activation energies is wider. It shows that thermal degradation of pine needles cannot be described by only one decomposition reaction. Therefore, there are no unique values of activation energy and frequency factor. As from comparing Tables 3 and Table 4, it can be concluded that the values of the activation energy and frequency factors are non-similar.

During the thermal decomposition of pine needles, which is a mixture of several organic materials, the threshold energy has to be attained. At the starting of the process, before initiating thermal degradation, molecular bonding is intact. Therefore, it is important to supply more energy (heat flux) to ensure the decomposition of these stable molecules. At high temperature interval, stable molecules decompose and less stable molecules which are easier to decompose are formed resulting in the reducing of heat flux. These molecules are formed at higher temperature and hence the value of activation energy reduces with increase of conversion rate. As from Fig. 6(b) and Table 3,it can be concluded that decrease of activation energy is consequence of decomposition of lignin.

TABLE 4. Kinetic PARAMETERS OBTAINED From MODIFIED DAEM EQ. (29) FOR PINE NEEDLES DECOMPOSITION

\begin{tabular}{llll}
\hline Eq. (29) parts & $\boldsymbol{\sigma}, \mathbf{k J} / \mathbf{m o l}$ & $\boldsymbol{E}_{\mathbf{0}}, \mathbf{k J} / \mathbf{m o l}$ & $\boldsymbol{A}_{\mathbf{0}}, \mathbf{s}^{\mathbf{1}}$ \\
\hline Hemi cellulose & 16.4418 & 138.1981 & $1.9815 \times 10^{26}$ \\
Cellulose & 9.87178 & 174.7720 & $2.9815 \times 10^{28}$ \\
Lignin & 17.5509 & 122.4232 & $3.0926 \times 10^{14}$ \\
\hline
\end{tabular}

\section{ConClusion}

The distribution activation energy model was used for mathematical modeling of pyrolysis decomposition of pine needles and the three main components of pine needles. The experimental data of sample residue mass fraction from thermogravimetric analysis were compared with simulated data obtained by the adopted optimization technique(asymptotic Eq. (26) and (28)). The decomposition temperature range of each substance was defined. Modified asymptotic equation was also used for evaluation of kinetic parameters of individual components of pine needles sample.

Mathematical investigation has been presented with the help of Matlab software and the accurate approximation of the double exponential temperature -dependent part of the double integral that arises in the DAEM, here called dexp, was evaluated. The two cases were discussed as: wide distribution and narrow distribution. After simulation, asymptotic approximations and numerical method for the mass fraction of decomposition were compared with the experimental results and have been found (for Gaussian distribution) asymptotic equations to be more accurate than previous approximation, particularly in the case of wide distribution. A numerical investigation of wide distribution for a model, Gaussian distribution indicates that the correction 
terms $B_{i}$ provide an improved estimate of the underlying distribution. Advantage of asymptotic methods discussed in this paper can be applied to any form of energy distribution (provided that it should be wide as to dexp), and to be applied for multiple distributions (as when different compounds with different mean and standard deviation are combined).

The obtained kinetic parameter values were compared with previous given solution of DAEM in literature. Besides evaluation of kinetic parameters, some other points were highlighted in this paper:

- Mathematical description of differential curves by asymptotic method for thermal decomposition of biomass;

- General problem with simulation of thermal decomposition of materials that comprise various other compounds (in case of differential dependence) as number of maximums are independent of behaviour of individual components with time.

\section{REFERENCES}

[1] Dhaundiyal A., Gupta V.K. The analysis of pine needles as a substrate for gasification. Journal of Water, Energy and Environment, Hydro Nepal 2014;15:73-81. doi: /10.3126/hn.v15i0.11299

[2] Burnham A.K, Braun R.L. Global kinetic analysis of complex materials. Energy Fuels 1999;13:1-22. doi: 10.1021/ef9800765

[3] Burnham A. K., Schmidt B. J., Braun R. L. A test of parallel reaction model using kinetic measurements on hydrous pyrolysis residues. Geochem 1995;23:931-939. doi: 10.1016/0146-6380(95)00069-0

[4] Galgano A., Blasi C.D. Modeling wood degradation by the unreacted-core-shrinking approximation. Ind. Eng. Chem. Res, 2003;42:2101-2111.doi: 10.1021/ie020939o

[5] Ferdous D, Dalai A.K, Bej S.K. Thring R.W. Pyrolysis of lignins: experimental and kinetics studies. Energy Fuels,2002;16:1405-1412. doi: 10.1021/ef0200323

[6] Khawam A., Flanagan D.R. Solid-state kinetic models: basics and mathematical fundamentals. Journal of Physical Chemistry B 2006;110:17315-1732. doi: 10.1021/jp062746a

[7] Vyazovkin S., Wight C. A. Model-free and model -fitting approaches to kinetic analysis of isothermal and non isothermal data. Thermochimica Acta. 1999;53:340-341. doi: 10.1016/S0040-6031(99)00253-1

[8] Nowicki L., Stolarek P., Olewski T., BedykT., Ledakowicz S. Mechanism and kinetics of sewage sludge pyrolysis by thermogravimetry and mass spectrometry analysis. Chemical and Process Engineering,2008;29:813-825.

[9] Mangut V., Sabio E., Ganan J., Gonzalez J. F., Ramiro A., Gonzalez C. M., Roman S., and A. Al-Kassir. Thermogravimetric study of the pyrolysis of biomass residues from tomato processing industry. Journal of Fuel Processing Technology 2006;87:109-115. doi: 10.1016/j.fuproc.2005.08.006

[10] Gunes M., Gunes S. A direct search method for determination of DAEM kinetic parameters from nonisothermal TGA data. Applied Mathematics and Computation2002;130:619. doi: 10.1016/S0096-3003(01)00124-2

[11] Sonobe T., Worasuwannarak N. Kinetic analyses of biomass pyrolysis using the distributed activation energy model. Fuel 2008;87(3):414-421. doi: 10.1016/j.fuel.2007.05.004

[12] Li Z., Liu C., Chen Z., Qian J., Zhao W., Zhu Q. Analysis of coals and biomass pyrolysis using the distributed activation energy model. Bioresource Technology2009;100:948-952. doi: 10.1016/j.biortech.2008.07.032

[13] Yan J. H., Zhu H. M., Jiang X. G., Chi Y., Cen K. F. Analysis of volatile species kinetics during typical medical waste materials pyrolysis using a distributed activation energy model. Journal of Hazardous Materials 2009;1;162-646. doi: 10.1016/j.jhazmat.2008.05.077

[14] Vand V. A theory of the irreversible electrical resistance changes of metallic films evaporated in vacuum.London:Proc. Phys. Soc., 1943.

[15] Pitt G. J. The kinetics of the evolution of volatile products from coal. Fuel 1962;41:267.doi: 10.1021/ef00002a002

[16] Hanbaba P., van Heek K.H., Jüntgen H., Peters W. Non-isothermal kinetics of coal pyrolyse, Part II: extension of the theory of the evolution of gas and experimental confirmation of bituminous coal. Fuel Chemistry 1968;49:368-376.

[17] Anthony D.B., Howard J.B. Coal Devolatilization and Hydrogasification. AIChE J. 1976;22:625-656. doi: 10.1002/aic.690220403

[18] Anthony D.B., Howard J.B., Hottel H.C., Meissner H.P. Devolatilization and Hydrogasification of Bituminous Coal. Fuel 1976;55:121-128. doi: 10.1016/0016-2361(76)90008-9

[19] Niksa S., Lau C. W. Global Rates of Devolatilization of Various Coal Types. Combust. Flame 1993;94:293. doi: 10.1016/0010-2180(93)90075-E 
[20] Miura K. A new and simple method to estimate $f(E)$ and $k 0(E)$ in the distributed activation energy model from three sets of experimental data.Energy \& Fuels 1995;9:302-7. doi: 10.1021/ef970212q

[21] Armstrong R., Kulesza B.L.J. An approximate solution to the equation $x=\exp (-x / \epsilon)$ ". Bull. Institute of Mathematics and its Applications, 1981;17:56.

[22] Varhegyi G., Szabo P., Antal M. J. Jr. Kinetics of charcoal devolatilization. Energy Fuels 2012;16:724-731. doi: $10.1021 / \mathrm{ef010227 \textrm {v }}$

[23] Suuberg E. M. Approximate solution technique for nonisothermal, Gaussian distributed activation energy models. Combustion and Flame 1983;50:243-245. doi: 10.1016/0010-2180(83)90066-4

[24] Howard J.B. In Chemistry of Coal Utilization. (M.A.Elliott, Ed) Wiley \& Sons, 1981.

[25] Bilbao R., Mastral J. F., Aldea M. E. Kinetic study for the thermal decomposition of cellulose and pine sawdust in an air atmosphere. J. Anal. Appl. Pyrol.3 1997;9:53-64. doi: 10.1016/S0165-2370(96)00957-6

[26] Sonobe T., Worasuwannarak N. Kinetic analyses of biomass pyrolysis using the distributed activation energy model.Fuel2008;87(3):414-421. doi: 10.1016/j.fuel.2007.05.004

[27] Muller-Hagedorn M., Bockhorn H., Krebs L., Muller U. A comparative kinetic study on the pyrolysis of three different wood species. Journal of Analytical and Applied Pyrolysis 2003;68-69:231-249. doi: 10.1016/S0165-370(03)00065-2

[28] Kastanaki E., Vamvuka D., Grammelis P., Kakaras E. Thermogravimetric studies of the behavior of lignite- biomass blends during devolatilization. Fuel Processing Technology2002:77-78:159-66. doi: 10.1016/S0378-3820(02)00049-8

[29] Gronli M. G., Varhegyi G., Di Blasi C. Thermogravimetric analysis and devolatilization kinetics of wood. Industrial \& Engineering Chemistry Research2002;41:4201-4208. doi: 10.1021/ie0201157

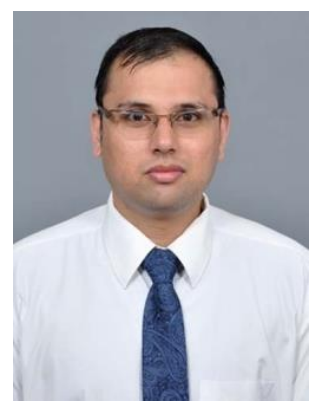

Author Alok Dhaundiyal had been awarded a Bachelor Degree (Mechanical Engineering) from Uttar Pradesh Technical University in 2009. He had completed a Master Degree in Mechanical Engineering with a major in Thermal Engineering from Govind Ballabh Pant University of Agriculture and Technology in 2014.

He has worked in the Deutsche Gesellschaft für Internationale Zusammenarbeit projects with collaboration of the Ministry of New Renewable Energy (MNRE) and the Uttarakhand Renewable Energy Development Agency (UREDA). He has also provided consultation to the Uttarakhand Forest Resource Management Project (UFRMP). He joined the Graphic Era Hill University as an Assistant Professor in the year 2014. Currently, he has been appointed as an Assistant Professor at Himgiri Zee University, Dehradun, Uttarakhand, India. His area of interest is the biowaste utilization for the power generation, gasification, applied mathematics and pyrolysis. He has published many research articles based on the 'Application of Mathematics in Biomass Pyrolysis'.

Author has been awarded 'GATE' scholarship by the Ministry of Human Resource and Development in the period of 2012-2014. In the year 2017, he has received 'Faculty of Engineering Excellence' by the University of Strathclyde, Glasgow, Scotland, United Kingdom.

Email id: alok.dhaundiyal@hzu.edu.in/, alok.dext@hotmail.com. ORCID: http://orcid.org/0000-0002-3390-0860.

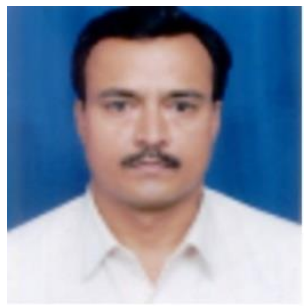

Dr. Pramod Chandra Tewari had been awarded a Bachelor degree in Mechanical Engineering from Govind Ballabh Pant University of Agriculture and Technology in the year of 1991. In 2008, he had completed a Master Degree in Mechanical Engineering with a major in Thermal Engineering from Govind Ballabh Pant University of Agriculture and Technology. He completed a Phd (Mechanical Engineering) degree in the year 2015 from Govind Ballabh Pant University of Agriculture and Technology.

From 1991 to 2003, he served in the Power plant Industry. He retired as a Senior Manager (Level 5) on 15 December 2003. He had been appointed as an Assistant Professor at Govind Ballabh University of Agriculture and Technology. Currently, He has been working as an Associate Professor in the Department of Mechanical Engineering, Govind Ballabh Pant University of Agriculture and Technology. Dr. P.C. Tewari has area of interest in Boiler operation and troubleshooting, and thermal power Plant.

$\mathrm{He}$ is a life time member of Indian Association of Nuclear Chemists and Allied Scientists (IANCAS). He received 'Field Excellence Award' for Boiler ESP.

Email: pramod2628@yahoo.co.in/, tewaripramod_chandra@rediffmail.com 